Journal of Contemporary Educational Research

Research Article

\title{
Improving Students' Humanistic Quality in the Teaching of Chinese Language and Literature in Vocational Higher Education Institution
}

Shijing Sun

Wuchang Branch of Harbin Radio and TV University, Harbin 150200, China

\begin{abstract}
Our country has a long history and culture. Teachers should actively promote the excellent Chinese traditional culture, do a good job of teaching and guidance, and effectively improve students' learning enthusiasm in the teaching of Chinese language and literature. However, the current Chinese literature taught in vocational higher education institution still has problems such as unclear educational goals, low curriculum status, and low level of informatization. Therefore, this paper fully studies and utilizes the advantages of vocational education on the premise of fully understanding the development goals of Chinese education in vocational higher education institution, enriching the content of Chinese language and literature education, strengthening Chinese language and literature education, and cultivating information ability. It is to help students better understand our country's fine traditional culture, guide students to establish correct learning concepts, and improve overall quality.
\end{abstract}

Keywords: Vocational higher education institution; Chinese literature; Teaching; Humanistic quality

Publication date: July, 2020

Publication online: 31 July, 2020

*Corresponding author: Shijing Sun, 1635833321@ qq.com

\section{Introduction}

With the continuous development of Chinese literature education, teachers of Chinese literature should give full attention to comprehensive guidance to students. We must make students become teachers, respect their individuality, use a variety of teaching methods, determine the characteristics of Chinese literature teaching, and innovate teaching. Courses about Chinese literature are closely related to the social life of students, and are the basic courses that guide students to realize lifelong education in vocational education. Courses related to Chinese literature have received more and more attention and recognition, with the continuous development of China's internationalization process. Since the implementation of the new curriculum reform, school education, especially higher education, has paid more attention to student education at the humanistic level. Chinese literature education has always been an important part of the education system of vocational higher education institution, and it plays an important role in improving the humanistic education of students ${ }^{[1]}$. Teachers are required to master the characteristics of Chinese literature, and conduct humanistic education for students of different personalities according to local conditions. It helps students to effectively understand the characteristics of Chinese language and literature, improve overall quality and learning concepts, and help students grow and develop in the future study and work.

\section{The value and significance of Chinese literature teaching in vocational higher education institution}

\subsection{Improving personal quality}

In the process of teaching instruction, teachers must fully clarify their educational goals and cultivate students' comprehensive qualities. It enables students to have a certain degree of professional knowledge, perfect personal qualities, and improve humanistic emotions. In the teaching process, teachers help students learn and explore effectively by using their own characteristics of knowledge of Chinese literature. In the learning process, students can better integrate their majors for improvement, which will help them learn and grow in the 
future.

\subsection{Cultivating students' humanistic concepts}

In the teaching of Chinese language and literature, teachers must combine teaching content with excellent literary works to improve students' cognitive ability. It is because Chinese textbooks are rich in cultural classics, for example ancient Confucianism. Teachers have more conversations with students, understand students' learning ability and emotions, and formulate educational goals according to students' comprehensive qualities, to better stimulate students' learning enthusiasm, and help students improve thinking ability ${ }^{[2]}$. Teachers can use exquisite articles and historical stories to guide their education and effectively attract students' attention. It can help students develop good study habits, cultivate learning emotions, and improve humanistic thinking.

\section{The promotion of Chinese literature teaching on humanistic quality}

\subsection{Cultivating students' emotion}

The outstanding language and literary works that enrich the spiritual world of our students are typical representatives of our traditional culture. At the same time, a good culture will infect and nurture students. By studying this beautiful chapter, you can easily stimulate the students' inner sense of literature. At the same time, they reflect on today's story and its growth, and cultivate their own humanistic emotions. Chinese literature education can help students find their learning direction, pursue spiritual beliefs, and enrich their spiritual world ${ }^{[3]}$.

\subsection{Improving students' cultural literacy and overall quality}

Chinese literature and literature can comprehensively improve the overall quality of students, so that they can better adapt to the training model of talents in society and meet the actual needs of society. As a student of Chinese language and literature, you will need to acquire four years of professional knowledge, improve your personal qualities and reading ability, and lay a solid foundation for learning more knowledge in the future in the process of learning Chinese language and culture, such as cultural heritage and broad literary vision. It guides students to find suitable learning models, establish correct learning concepts, clarify learning goals, stimulate students' enthusiasm, and innovate educational management mechanisms. A positive outlook on life, world outlook and values are the three outlooks that every student should have. Chinese language and literature education in higher vocational colleges can not only help students learn theoretical knowledge, but also cultivate students' emotions and improve their practical skills through excellent poetry classics, literary education activities, tea parties, reading clubs and other methods.

\subsection{Cultivating students' patriotism, national identity and social responsibility}

Chinese education in vocational higher education institution is to improve the comprehensive quality of students by teaching multiple languages and literature. In fact, this is a process of developing students' humanities. Due to the influx of foreign cultures and students' comparison and pursuit of material culture, some students obviously lack patriotism and a sense of social responsibility, so it is very important to cultivate patriotism and a sense of social responsibility. In the process of Chinese language and literature teaching in vocational higher education institution, we must first cultivate students' patriotism, national identity and social responsibility, which are the source of all humanistic qualities and cultural awareness. From ancient times to the present, literary creators have revealed their feelings about the country. This is an opportunity to improve students' communication skills and an important way to improve students' artistic achievements. In this regard, students should work hard to learn Chinese and literature knowledge to improve their overall quality and independent learning ability.

\subsection{It helps to improve students' personal temperament}

In the process of studying Chinese literature, students can not only appreciate the excellent ancient and modern works from home and abroad, but also experience and understand the thought and spirit of excellent writers, as well as the charm of literature and knowledge. The beautiful artistic conception of Chinese knights can not only cultivate students' emotions, but also improve students' aesthetic ability, thereby enhancing humanistic temperament, which is also an important part of humanistic quality education in colleges and universities ${ }^{[4]}$. Humanities level education includes various contents and is a complex level education covering all cultures, civilizations and progress. The humanistic quality of students can be summarized as a part of the comprehensive quality of students.

\section{Analysis of Problems Existing in Chinese Language and Literature Teaching in Higher Vocational Education}




\subsection{The teaching model is rigid}

The focus of higher vocational language education is to learn humanistic knowledge to improve students' humanistic quality. The purpose of traditional Chinese literature is to teach students Chinese theoretical knowledge, analyze the structure of the passages, and understand the thought. However, the humanistic ideas in textbooks have not been taken seriously in a result that students cannot understand the profound humanistic emotions in the text. It does not help improve the humanities of students.

\subsection{Learning interest of vocational students}

The task of higher vocational students is to study professional courses, Chinese literature and literature are not the core courses of their majors. Therefore, many students are not interested in learning Chinese language and literature and even think that it has little effect on their professional knowledge learning. There are many passages in Chinese textbooks for students to read. Many students are not interested in reciting texts. Therefore, students are usually not interested in learning Chinese literature.

\subsection{Restrictions on corresponding trial education}

The talents of examination-driven education and training lack humanistic care and cannot adapt to the needs of the times. In a market economy, the social environment may be more complex and changeable. By actively seeking teaching methods, changing learners' learning attitudes and improving humanistic qualities, educators can adapt to social development. Due to the influence of performance education and test-oriented education, it is difficult for schools to improve students' humanistic quality only through classroom teaching.

\section{Measures and suggestions for cultivating students' humanistic quality}

\subsection{Understanding the important role of Chinese literature education}

Chinese literature occupies an important position in the core curriculum of the humanities. First, Chinese literature education can enrich the spiritual life of students. Secondly, Chinese literature has many ancient wisdoms. Students can improve self-expression and communication skills through rich literary knowledge and communication skills. Finally, students can experience and absorb nutrition in the process of interacting with various literary works and fully grasp the excellent traditional Chinese culture through Chinese literature education which cultivates the emotions of students in vocational higher education institution, and provide correct outlooks of value, life and world. Once it is established, students can learn in the process to improve the humanistic quality of students in vocational higher education institution.

\subsection{Creating a specific teaching plan to improve teaching efficiency}

In Chinese and literature education, teachers create a corresponding educational environment, effectively stimulate students' learning enthusiasm, and enhance students' learning enthusiasm in line with the interests of students. In addition, teachers and students have more conversations to reduce the distance between students, and create corresponding teaching situations according to the students' learning conditions and the content of professional courses, so that students can feel the charm of Chinese language and literature and bury themselves into it. You need to stimulate the senses. Teachers use the literary characteristics and cultural meanings of Chinese literature to provide teaching guidance, so that students have a deeper understanding of the beauty of Chinese literary context, improve students' understanding of Chinese culture, enhance aesthetic awareness, and enhance humanistic spirit. Increase the acceptance of quality education.

\subsection{Connecting with the reality of life and stimulate students' interest}

Teachers should not only pay attention to the educational status quo of the humanistic level of students in the spiritual world, but also connect with the actual social life. From their own point of view, they extract relevant content from social life cases that are helpful to article education, actively educate students from the humanistic level, and stimulate students' interest in learning human knowledge. For example, in the teaching of "Necklace", the teacher will not only explain the complex psychology of the protagonist, but also incorporate the psychology of certain social roles in the necklace into classroom teaching to study why the role and the fate of the role will change when students study this article. Must be able. The philosophical nature of destiny leads the story. Taking the master as an example, establishes a correct outlook on life and values, and cultivates students' humanistic qualities.

\section{Conclusion}

At present, our country pays more and more attention to the cultivation and management of students' human- 
ities. The role and status of higher vocational colleges in the education system is essential. It is also an important task to improve the quality of the people and promote lifelong education. Therefore, we must improve the humanistic quality of college students and make full use of this in future work so that they can grasp the direction of life. Through continuous improvement of the curriculum structure and education system, students' interest in learning Chinese literature has been effectively improved, and students' Chinese reading ability and comprehensive quality have been comprehensively improved.

\section{References}

[1] Ma XP. Improving the humanistic quality of students in the teaching of Chinese language and literature in higher vocational schools[J]. Window of Knowledge (Teacher Edition), 2020(8): 27.

[2] Hu SY. Problems and countermeasures in the teaching of Chinese language and literature in higher vocational schools[J]. Hundreds of Prose (New Chinese Loose Leaf), 2020(8): 162163.

[3] Xu Y. Based on the study of the relevance of Chinese language and literature and higher vocational Chinese education [J]. Hundreds of Prose (Theory), 2020 (04): 141.

[4] Li TF, Shabira MW. The role of aesthetic education in Chinese language and literature teaching in higher vocational schools[J]. Qiaoyuan, 2020(1): 112. 